\title{
The Separation of a Binary Water/Ethanol Solution via a Continuous Feed Distillation Column as a Function of Feed Stage Location and Reflux Ratio
}

\author{
Moutaz M. A. Eldirderi \\ Department of Chemical Engineering, Faculty of Engineering, King Khalid University, Saudi Arabia
}

\begin{abstract}
The purpose of this study was to investigate the separation of a binary water/ethanol solution via a continuous feed distillation column as a function of feed stage location and reflux ratio. The column was initially run with the feed entering at the first stage under reflux ratios of 7.3 and 2.36. The composition of the distillate and liquid product were recorded and compared with theoretical results predicted by the McCabe-Thiele graphical method. In addition, the effect of feed stage location was examined by feeding into the fifth stage while at a reflux ratio of 7.3. It was found that the distillate composition was approximately 20\% (by weight) at a reflux ratio of 7.3 , whereas this value dropped to $15 \%$ when running at a reflux ratio of 2.36 . Although a higher reflux ratio is desired to produce a higher concentration of ethanol in the distillate, it must be considered that a higher reboiler duty, and in turn a higher operating cost, is required to accomplish this. It was also observed that changing the feed location to the fifth stage resulted in a decreased ethanol concentration in the distillate. Finally, it was found that for the distillate compositions attained in this experiment, the McCabe-Thiele graphical method predicted significantly fewer stages than found in the laboratory column. This indicates that a high inefficiency exists in the stages of the column and these factors should be further investigated.
\end{abstract}

Keywords: Feed stage; Distillation; reflux ratio; binary; Software; experiment.

\section{Introduction}

This experiment was designed to determine the impact of certain variables on the performance of a continuous distillation column in which an ethanol/water mixture is separated. The particular variables examined were the location of the feed stage in the column and the reflux ratio. Through determination of the optimum process parameters, the column can be run in a way that will produce the desired product in the most efficient and economical way, thus decreasing operating costs and therefore maximizing profitability.

In order to determine the optimum combination of these variables, the column was run with two different feed entrance locations, as well as two different reflux ratios. The outlet stream data for each scenario was recorded and compared to results obtained from the McCabe-Thiele graphical method, which provides the theoretical number of stages necessary to achieve a particular product composition. By doing this comparison, it can be seen how many additional stages were necessary to achieve that composition in the actual process, and the efficiency of the process can be determined.

\section{Theory}

Distillation is a method used to separate components based on their presence in both the liquid and vapor phases, where all components exist in both phases. Separation of the components is achieved through differences in boiling points between the species, however since concentration will affect the boiling point of the liquid phase, the process is also dependent on the vapor pressure of the components.

Distillation columns are therefore designed based on vaporliquid equilibrium data, and one of the most common methods used for design purposes is the McCabe-Thiele graphical method. This method is based on the assumption of equimolar overflow, meaning that for every mole of liquid that is vaporized, a mole of vapor condenses. This assumption also implies that the components have similar molar heats of vaporization.

By graphing the equilibrium curve for the mixture in question, the McCabe-Thiele method can be applied to determine the theoretical plates needed for the column. Once the equilibrium curve is obtained, operating lines that identify the mass balance relationship between the liquid and vapor phases must be plotted. There are two operating lines, one representing the section of the column above the feed, or the enriching section, and one representing the section of the column below the feed, or the stripping section. In order to obtain theses operating lines, the reflux ratio, or amount of top product returned to the column, must be known. This value can be obtained using the following equation

$$
R=\frac{L}{D}
$$

where $\mathrm{L}$ is the reflux flow rate and $\mathrm{D}$ is the distillate flow rate.

Using the calculated reflux ratio, the enriching operating line was plotted using the following equation

$$
y_{n+1}=\frac{R}{R+1} x_{n}+\frac{x_{D}}{R+1}
$$

where $\mathrm{y}_{\mathrm{n}+1}$ is the composition of the vapor entering stage $\mathrm{n}$, $\mathrm{x}_{\mathrm{n}}$ is the composition of the liquid leaving stage $\mathrm{n}$ and $\mathrm{x}_{\mathrm{D}}$ is the composition of the distillate. Refer to the Appendix for calculations.

A diagram of the enriching operating line can be seen in Figure 1. As can be seen in the equation, the line will

\section{Volume 4 Issue 12, December 2015}




\section{International Journal of Science and Research (IJSR) \\ ISSN (Online): 2319-7064}

Index Copernicus Value (2013): 6.14 | Impact Factor (2014): 5.611

intersect the y-axis at $\frac{x_{D}}{R+1}$ and will have a slope of

$$
\frac{R}{R+1} \text {. }
$$

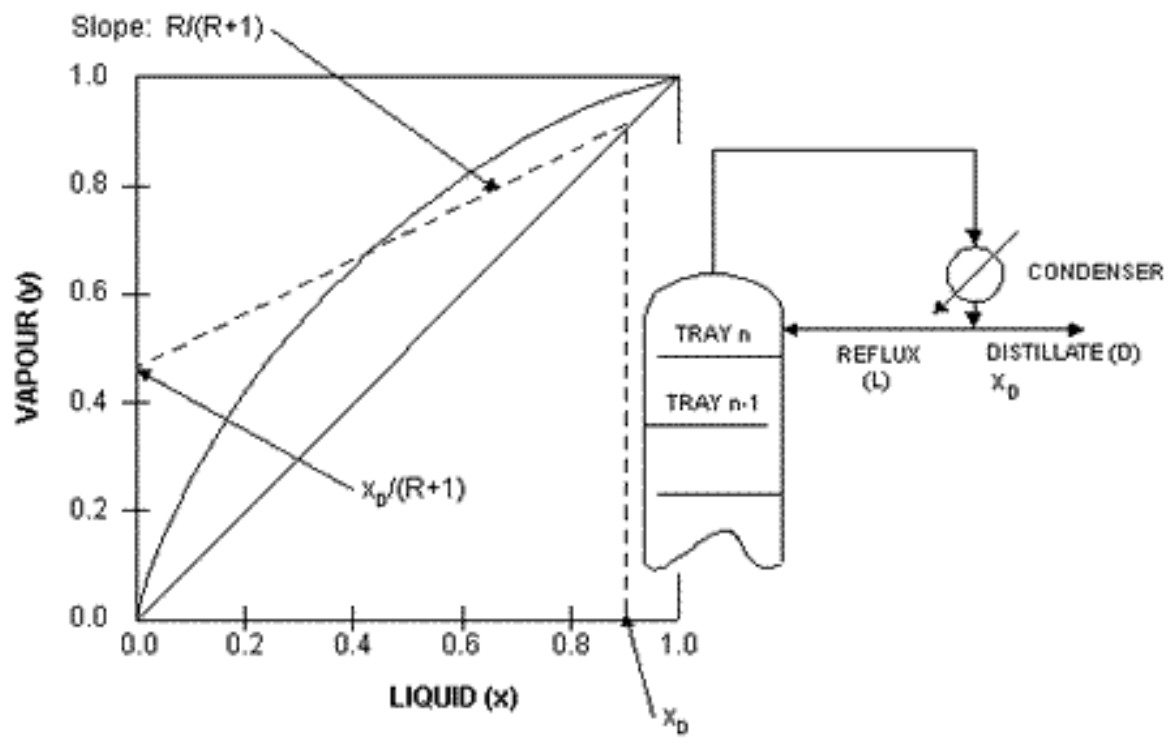

Figure 1: Enriching Section Operating Line Diagram

Before plotting the stripping section operating line, the qline, or line describing the feed conditions, can be plotted. The q-line is determined by first calculating the value of $q$ through use of the equation below

$$
q=\frac{H_{v}-H_{F}}{H_{v}-H_{L}}
$$

where $H_{v}$ is the enthalpy of the feed at the dew point, $H_{F}$ is the enthalpy of the feed at the boiling point, and $\mathrm{H}_{\mathrm{L}}$ is the enthalpy of the feed at its entrance condition. This quantity can be found via hand calculation or through the use of ChemCad software. Using the software, data can be obtained for the amount of heat necessary to vaporize an ethanol/water mixture at the feed conditions used in the experiment. The value for $\mathrm{q}$ can then be found by dividing the total heat needed to vaporize the feed from its entrance conditions by the amount of heat needed to vaporize the feed

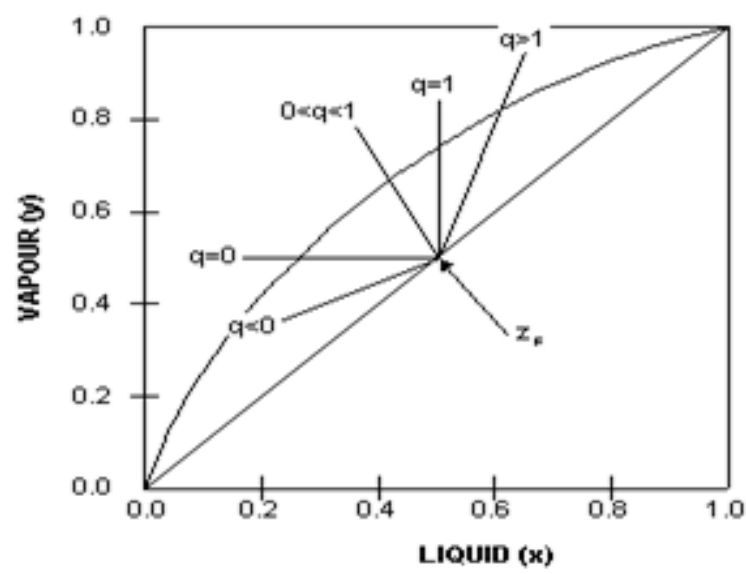

Figure 2: Diagram of q-lines for various feed conditions

Since the enriching section operating line and the q-line are known, the stripping section operating line can be plotted by simply drawing a line between the point where the q-line from its boiling point. This graph can be seen in the Appendix.

Once the value of $\mathrm{q}$ is determined, the slope of the q-line can be determined using the following equation:

$$
\text { slope }=\frac{q}{q-1}
$$

It can be seen that Eq. 3 will go to zero if the feed is at its boiling point, and the slope of the line will therefore go to infinity and be a vertical line. The slope of the q-line can be predicted in a similar manner for other feed conditions. For liquids below the boiling point, as in this experiment, it is expected that $\mathrm{q}$ will be greater than one and therefore the slope of the line will be greater than one. Figure 2 shows various q-lines and their corresponding feed conditions.

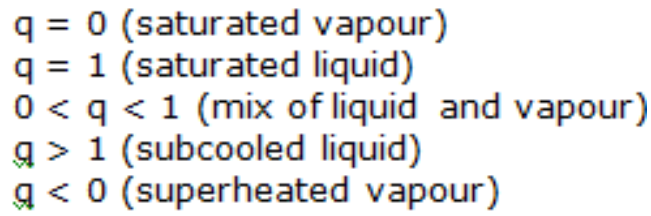

and equilibrium line intersect and the point $\mathrm{x}_{\mathrm{b}}$, which is the desired composition of the bottoms. 


\section{International Journal of Science and Research (IJSR) \\ ISSN (Online): 2319-7064}

Index Copernicus Value (2013): 6.14 | Impact Factor (2014): 5.611

Once all of the necessary lines are obtained, the number of theoretical stages can be found by "stepping-off' the graph. Beginning on the enriching section operating line at the point $\mathrm{x}_{\mathrm{D}}$, a line is drawn horizontally until the equilibrium curve is reached. At this point, a vertical line is drawn downward until arriving at the enriching section operating line again. This process is continued until the point where the enriching section and stripping section operating lines join. At this point, the vertical lines switch from the enriching line to the stripping line. In addition, the stage where this transition takes place is the optimum feed stage according to this method. An example of this 'stepping-off' process can be seen in Figure 3.

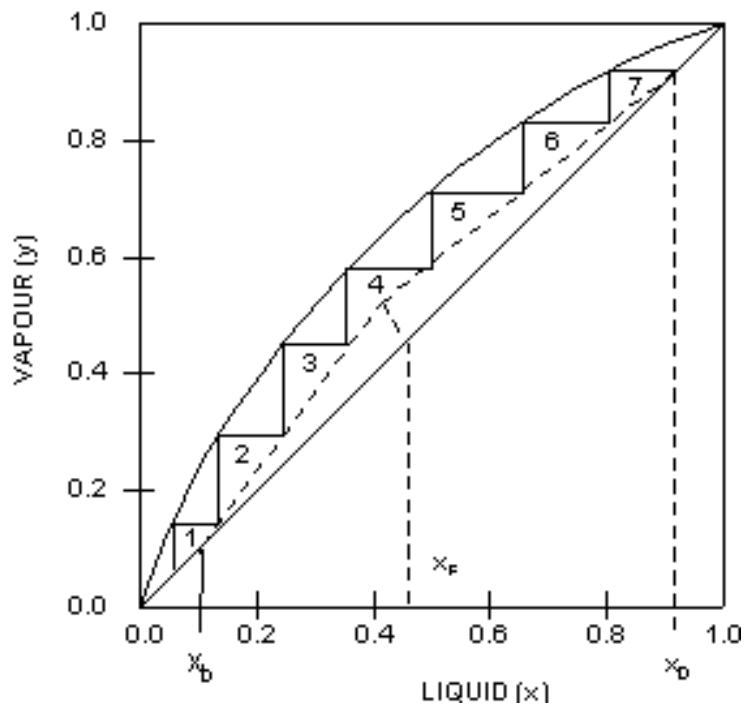

Figure 3: Example of stepping off stages using the McCabeThiele method

Since ethanol is a appreciably more volatile than water, it is expected that a small number of stages will be necessary to separate these components. In addition, it is known that under maximum reflux, where the entire top product is continuously returned to the column as reflux, the number of stages required to reach a desired purity is at a minimum. Therefore, it is expected that when using a fixed number of stages, as with the laboratory column, a higher reflux ratio will result in a higher distillate purity.

\section{Apparatus and Procedure}

The experiments were conducted with a 10 stage, bubble cap Mooney Process Equipment distillation column. Figure 1 shows the flow direction and nomenclature for a distillation column very similar to the one used in the experiment. The column was operated with a total condenser for the distillate with an $8000 \mathrm{~W}$ (max duty) reboiler. The feed to the column was pumped from a 72 liter feed well vessel with variable heating. The reflux (shown as $\mathrm{L}_{\mathrm{N}+1}$ in Figure 1) was returned to the column through a glycol solution heating bath to raise the temperature of the solution after condensing. The column temperature profile was recorded from thermocouples located at each tray. Feed and distillate compositions were monitored through in-line refractometers. Other relevant characteristics of the column are as follows:

$\begin{array}{ll}\text { Material of Construction: } & \text { Glass } \\ \text { Column Diameter: } & 3 \text {, outside diameter } \\ \text { Column Height: } & 10 \text { stage } \\ \text { Tray Type: } & 3 \text { in bubble cap } \\ \text { Feed and Reboiler Volume: } & 72 \text { liter }\end{array}$

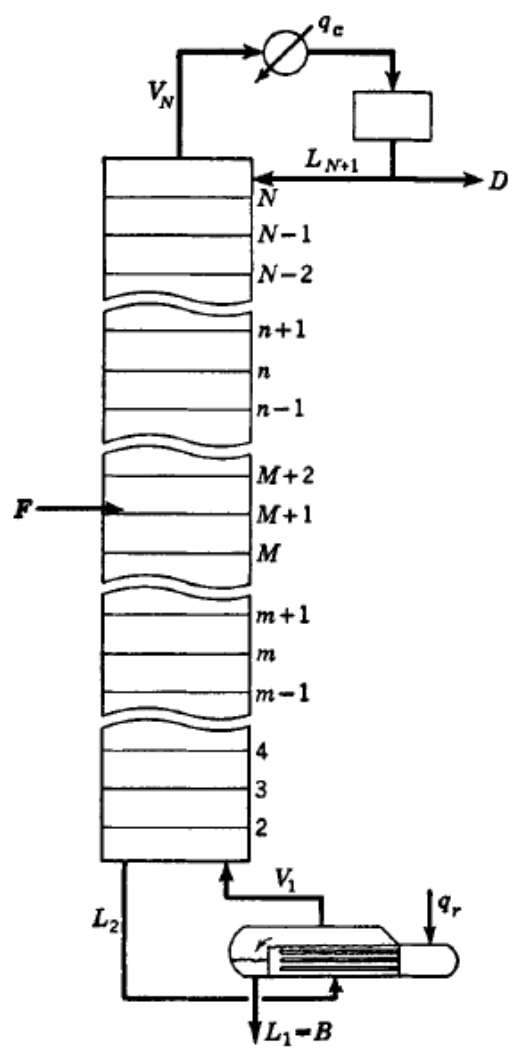

Figure 4: Schematic Diagram for a Continuous Feed Distillation Column (Perry's)

Start up of the column prior to operation consisted of monitoring both the feed vessel and reboiler temperatures until the set point temperatures were reached. The reboiler contained an initial volume of solution prior to start up. Typical set point temperatures for the feed vessel and reboiler were 70 and $110{ }^{\circ} \mathrm{C}$, respectively. While the feed vessel and reboiler were heating to the set point, the cooling water to the condensers on the distillate, bottom product, and feed well vent lines was turned on. The feed well to the column is vented to avoid pressure buildup and must be condensed to avoid loss of ethanol when heating. The feed solution was then directed to enter into the desired stage (1 through 10).

For this study, two experiments were run with the feed entering at stage 1 and a third was run with the feed at stage 5 , with stage 1 being closest to the reboiler and stage 10 the furthest. The set point temperature for the reflux line heating bath was set at $110{ }^{\circ} \mathrm{C}$ for all experiments. Once product was seen condensing in the collection vessel, the feed and reflux line pumps were turned on and the column was considered to be in continuous operation. The temperature profile of the column was monitored and recorded periodically during operation by thermocouples located at each stage. The distillate concentration was monitored by an in-line refractometer. When the temperature profile and distillate concentration were constant, the column was said to be a steady state operation. 


\section{International Journal of Science and Research (IJSR) \\ ISSN (Online): 2319-7064 \\ Index Copernicus Value (2013): 6.14 | Impact Factor (2014): 5.611}

Once the column reached a steady state, the flow rates of the distillate and bottom product were measured volumetrically. The distillate and bottom product were allowed to fill their respective collection vessels over a period of time (typically 5 minutes), from which the volumetric flow rates could be determined. With no direct flow rate measurement of the feed, the solution level in the reboiler was monitored at constant level such that the feed flow rate could then be determined by the sum of the distillate and bottom product flow rates. At the end of each experiment the collected solutions were pumped back to the feed vessel so that refilling of the system was not required.

\section{Results}

The data obtained in the experiment can be seen in Table 1 . Raw data can be found in the Appendix.

Table 1

\begin{tabular}{|c|c|c|c|c|c|c|}
\hline \multicolumn{7}{|c|}{ Experimental Results } \\
\hline & $\begin{array}{c}\text { Distillate } \\
\text { Flow Rate } \\
(\mathrm{ml} / \mathrm{min})\end{array}$ & $\begin{array}{c}\text { Reflux } \\
\text { Flow Rate } \\
(\mathrm{ml} / \mathrm{min})\end{array}$ & $\begin{array}{c}\text { Bottoms } \\
\text { Flow Rate } \\
(\mathrm{ml} / \mathrm{min})\end{array}$ & $\begin{array}{c}\text { Weight \% } \\
\text { Ethanol } \\
\text { in Distillate }\end{array}$ & $\begin{array}{c}\text { Mole \% } \\
\text { Ethanol } \\
\text { in Distillate }\end{array}$ & $\begin{array}{c}\text { Weight \% } \\
\text { Ethanol } \\
\text { in Bottoms }\end{array}$ \\
\hline $\begin{array}{c}1^{\text {st }} \text { Stage Feed } \\
7.3 \text { Reflux Ratio }\end{array}$ & 18.6 & 35.7 & 110 & 20 & 10 & 0 \\
\hline $\begin{array}{c}1^{\text {st }} \text { Stage Feed } \\
2.36 \text { Reflux Ratio }\end{array}$ & 44 & 104 & 103.3 & 15 & 7.24 & 0.5 \\
\hline $5^{\text {th } \text { Stage Feed }}$ 7.3 Reflux Ratio & 46.8 & 104.3 & 136.4 & 13 & 6.11 & 1.5 \\
\hline
\end{tabular}

Using the ChemCad software, equilibrium data was acquired for the ethanol/water mixture and a x-y diagram was plotted. This graph is shown below in Figure 5.

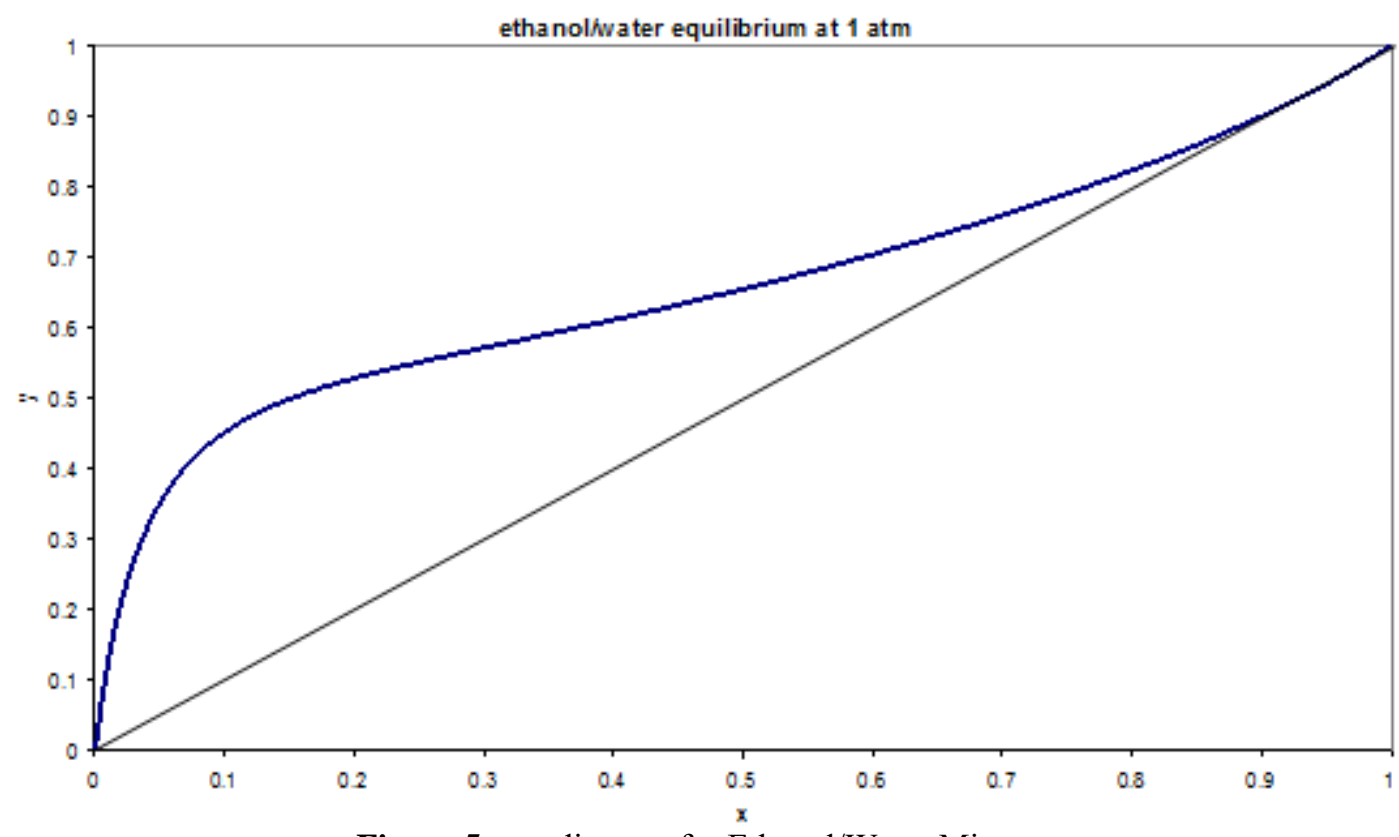

Figure 5: $x-y$ diagram for Ethanol/Water Mixture

via bottoms flow rate $(\mathrm{ml} / \mathrm{min})$ was plotted. This graph is Using the excel software, equilibrium data was acquired for shown below in Figure 6. 


\section{International Journal of Science and Research (IJSR)

- Bottoms Flow Rate (ml/min)

Distillate Flow Rate (ml/min)

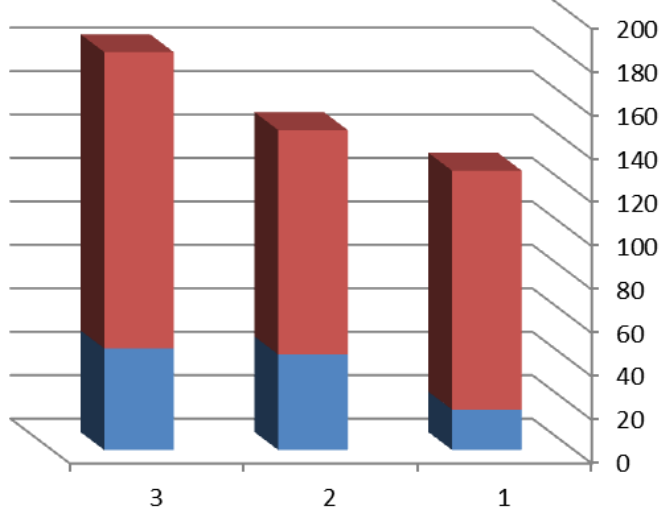

Figure 6: distillate flow rate $(\mathrm{ml} / \mathrm{min})$ via bottoms flow rate $(\mathrm{ml} / \mathrm{min})$ diagram

\section{Discussion}

It can be seen in Table 1 that the experimental results were generally consistent with expected trends. As the reflux ratio was increased from 2.36 to 7.3 , the concentration of ethanol in the distillate increased from $15 \%$ to $20 \%$. It was also found that for the same reflux ratio, as the feed stage was moved from the first to the fifth stage the concentration of ethanol in the distillate decreased.

As expected, the McCabe-Thiele graphical method predicted a far fewer number of stages for the distillate compositions in question than the number of trays found in the laboratory column. While it is expected that there will be some discrepancy between the theoretical and actual number of stages, this is a significant difference. Since the graphical method includes the reboiler in the number of stages, the theoretical number of stages is actually one less than the value obtained from the graph. Therefore, the McCabeThiele method predicts only one stage necessary for the compositions reached in this experiment. The McCabeThiele diagrams for each case can be seen in Figures 6,7 and 8 respectively. The high level of inefficiency present in the laboratory column can be attributed to several different factors. First, the theoretical method assumes no heat loss from the column. Although the column is insulated, it is probable that there is still some degree of heat lost to the atmosphere. In addition, it is assumed that there is adequate contact time at each tray for the liquid and vapor phases to leave in equilibrium. This is an ideal case assumption and it is likely that this is not achieved in the laboratory column. It is possible that running a lower feed rate would allow more contact time at each stage and therefore create better exchange between the two phases. Finally, it is certain that there is a degree of experimental error in the results, which may also account for some of the inefficiency of the column.

It can be seen in Figure 6 that the experimental results show that the bottom flow rate high than distillate flow rate.

\section{Conclusions and Recommendations}

The investigation of variables affecting the continuous distillation column showed two clearly evident trends. First, when feeding to a particular stage, increasing the reflux ratio results in an increased ethanol concentration in the distillate. (Refer to Table 1)

The second trend noted was that changing the feed from the first to the fifth stage decreased the ethanol concentration in the distillate. This trend, however, should be further investigated since only one sample was taken for this scenario. (Refer to Figure 6)

It was also found that the number of stages predicted by the McCabe-Thiele graphical method was significantly lower than the number found in the laboratory column for the compositions obtained in this experiment. This indicates a large inefficiency in the performance of the laboratory column. This inefficiency may be due to several factors, including heat loss from the column and Based on the observed trends, it is recommended that the trade-off between increased product purity from the use of a higher reflux ratio and the resulting increase in reboiler duty be further investigated. By doing so, it may be determined the optimum reflux ratio at which to run the column. It is also recommended that the location of the feed stage be further investigated since it is typically expected that a feed near the middle of the column is best. Since only one sample was taken for the fifth stage feed, it is difficult to determine whether the resulting data was accurate. By running another sample at the same conditions, it can be determined whether the lower product purity is a consistent result and should be considered when designing the column operating parameters. Finally, it is suggested that a lower feed flow rate be investigated since only one feed rate was used in this experiment. This may allow longer contact time at each tray and therefore a better equilibrium between the phases leaving the tray.

\section{References}

[1] Geankoplis, Christie J., "Transport Processes and Unit Operations," $3^{\text {rd }}$ ed., Prentice Hall (1993).

[2] Perry, Robert H., and Don W. Green. "Perry's Chemical Engineers' Handbook" $7^{\text {th }}$ ed. New York: McGraw-Hill Inc., (1997)

[3] Introduction to Distillation. http://lorien.ncl.ac.uk/ming/distil/distildes.h

[4] Kister, Henry Z. Distillation Design (1st Edition ed.). McGraw-hill. (1992). 


\section{International Journal of Science and Research (IJSR) \\ ISSN (Online): 2319-7064}

Index Copernicus Value (2013): 6.14 | Impact Factor (2014): 5.611

[5] M.T.Tham, Distillation an introduction "Distillation column design"(1998)

[6] R.K.Sinnolt1993;Chemical Engineering Volume6 Pergaman press-Oxford,NewYourk,Toranto,Paris \&Sydeny 